\title{
The effects of roadway characteristics on farm equipment crashes: a geographic information systems approach
}

\author{
Mitchell Greenan ${ }^{1}$, Maisha Toussaint ${ }^{1}$, Corinne Peek-Asa', Diane Rohlman² and Marizen R. Ramirez ${ }^{1,2^{*}}$
}

\begin{abstract}
Background: Tractors and other slow-moving self-propelled farm equipment are often used on public roadway to transfer goods from the farm to a market or distributer. Increased roadway exposure has led to a growing concern on the occurrence of farm equipment crashes. This study aims to compare characteristics of road segments with farm equipment crashes to road segments without farm equipment crashes in the state of lowa.

Methods: Data were obtained from the lowa Department of Transportation from 2005 to 2011 on all crashes involving farm equipment, and features of all lowa roadways. Geographic Information Systems (GIS) was used to identify geospatial features, such as road type, speed limit, traffic volume surface type, road and shoulder width of where a crash occurred. Logistic regression models were used to measure the associations between road characteristics and the occurrence of farm equipment crashes. Crude and adjusted odds ratios and 95\% confidence intervals were reported.

Results: A total of 1371 farm equipment crashes were reported in lowa over the 6-year period and geocoded onto a street location. As traffic volume increased, the odds of a crash occurring also increased. Roadways with posted speed limits between 50 and $60 \mathrm{mph}$ were associated with a higher odds of having crashes on them compared to roadways with speeds less than $35 \mathrm{mph}(\mathrm{OR}=8.05,95 \% \mathrm{Cl}$ : 6.59-9.84). lowa routes ( $\mathrm{OR}=5.98,95 \% \mathrm{Cl}$ : 4.97-7.20) had the highest odds of having crashes compared to local routes. Increased road width ( $\mathrm{OR}=0.90,95 \% \mathrm{Cl}: 0.86-0.94)$ was associated with a $10 \%$ decrease in the odds of a crash.

Conclusions: Higher traffic volume, higher posted speed limits, road type, and smaller road widths were associated with the occurrence of farm equipment crashes. Findings from this study can be used to guide policy to improve roadway design and conditions for all road users.
\end{abstract}

Keywords: Traffic safety, Agricultural vehicles, Transportation, Road crashes

\section{Background}

In the United States, transportation-related incidents accounted for half of all agricultural worker fatalities in 2014, and of these incidents approximately $27 \%$ were due to crashes occurring on public roadways (Bureau of Labor Statistics U.S. Departement of Labor 2015). According to the Iowa Department of Transportation (IDOT) crash reports from 2004 to 2014, 2108 farm equipment crashes occurred on public roadways that resulted in 660 injuries

\footnotetext{
* Correspondence: marizen-ramirez@uiowa.edu

${ }^{1}$ University of lowa Injury Prevention Research Center, Department of

Occupational and Environmental Health, University of lowa College of Public Health, lowa City, IA 52242, USA

${ }^{2}$ Department of Occupational and Environmental Health, Rm S318, University of lowa College of Public Health, lowa City, IA 52242, USA
}

and 79 fatalities (Iowa Department of Transportation 2015). Operating tractors and other slow-moving farm equipment on public roadways places agricultural workers at risk for collisions (Gerberich et al. 1996) and injuries. However, farm equipment crashes are not only an occupational hazard but also pose a significant threat to non-agriculture road users. Over a 10 -year period, approximately $82 \%$ of farm equipment crashes involved non-farm vehicles, and among those resulting in at least one driver injury, drivers of non-farm vehicles were five times more likely to be injured than the farm equipment operators (Peek-Asa et al. 2007), demonstrating the need or urgency to develop and implement preventive measures.
Springer Open

(c) The Author(s). 2016 Open Access This article is distributed under the terms of the Creative Commons Attribution 4.0 International License (http://creativecommons.org/licenses/by/4.0/), which permits unrestricted use, distribution, and reproduction in any medium, provided you give appropriate credit to the original author(s) and the source, provide a link to the Creative Commons license, and indicate if changes were made. 
Due to the severity of farm equipment crashes on public roadways, federal and state laws have been implemented but often require action with a focus on and at the expense of farmers. The mandatory use of appropriate equipment, lighting and vehicular signage to improve the safety and conspicuity of farm equipment on the roadway has been implemented in several states including Iowa, but enforcement is lacking (Committee on Agricultural Safety and Health Research and Extension 2009). Despite the fact that at least $88 \%$ of farmers reported lighting and marking their farm equipment according to regulatory standards (Luginbuhl et al. 2003), lack of visible signage and below-standard lighting remains a concern (Committee on Agricultural Safety and Health Research and Extension 2009; Kinzenbaw 2008).

State lighting and marking laws require individual behavior change on the part of the farm equipment operator. However, approaches to transportation safety research focus instead on identifying dynamic characteristics of the environment or the infrastructure of the roadway that predict the risk of a crash (Hadi et al. 1995; Karlaftis \& Golias 2002). Ultimately, environmental infrastructure research can identify improvements in roadway design that can lead to significant reductions in the rate or severity of crashes. Recent roadway-based crash prediction models have consistently found that traffic volume (Hadi et al. 1995; Karlaftis \& Golias 2002; Ackaah \& Salifu 2011) was a significant predictor of motor vehicle crashes. Other road characteristics such as lane width, serviceability index (road quality), access control, pavement type (Karlaftis \& Golias 2002), increased road segment length, terrain type (Ackaah \& Salifu 2011), and shoulder width (Hadi et al. 1995) were also found to be significantly associated with the occurrence of a crash across studies. While these findings have been extremely important to the fields of transportation safety and public health, few studies have assessed the role of road characteristics on the risk of farm equipment crashes.

The few agriculture transportation-based studies report that farm equipment crashes frequently occur on roads with greater traffic volume (Costello et al. 2009), unpaved roads (Gerberich et al. 1996), roads in urban zip codes (Harland et al. 2014), two-lanes or county highways, and on roads with $55 \mathrm{mph}$ posted speed limits (Gerberich et al. 1996; Peek-Asa et al. 2007; Gkritza et al. 2010). Although these studies have contributed to our knowledge concerning the challenges of operating farm equipment on roadways, there are important limitations to consider. One important limitation in crash report analyses is the lack of exposure information, which is necessary to estimate crash risk. To address this limitation, we analyzed farm equipment crash risks at the road-segment level and used Geographic Information Systems (GIS) to identify spatial attributes of road segments with and without crashes. The aim of this study was to investigate roadway characteristics that are associated with farm equipment crashes on Iowa roadways. We compared characteristics of road segments where farm equipment crashes occurred to road segments where there were no farm equipment crashes.

\section{Methods}

\section{Data source}

Data on all crashes involving farm equipment on public roads in Iowa from 2005 to 2011 were obtained from the IDOT. Farm equipment was defined as vehicles designed specifically for agricultural operation (2014) such as combines, farm tractors, fertilizers, feeders, towed grain carts, and wagons. Although pick-up trucks can be used as farm equipment, we excluded them because we could not verify the purpose of use. From the crash data that include crash latitude and longitude, each reported crash was geocoded using GIS to provide a geographic view or visualization of where farm equipment crashes occurred throughout the state. Each crash was then linked to a road segment. Of the 1401 farm equipment crashes, 12 were coded as passenger vehicles based on vehicle identification numbers, and 18 records were missing address-based data and were excluded resulting in a final sample size of 1371. Rather than using the crash as the unit of analysis, we used the road segment on which the crash occurred. Road segment data were provided by the Environmental Services Research Institute (ESRI). Roads were demarcated into segments each time any of the road characteristics (e.g., type of road, speed, and road width) changed (see Appendix). The IDOT road network spatial dataset created in 2007 of Iowa roads (primary, secondary, and municipal roads) containing information describing the road segments was used for this study. All study procedures were reviewed and approved by the University of Iowa Internal Review Board.

\section{Study population}

The original dataset consisted of 324,769 road segments collected by the IDOT. Approximately two percent of the original dataset had missing data for speed limit $(n=5064)$, road width $(n=4139)$ and surface type $(n=3871)$. The removal of these records resulted in a final sample at 319,705 road segments.

\section{Study variables}

The outcome, road segments where a farm equipment crash occurred, was defined as a public Iowa roadway where a vehicular crash involving at least one piece of farm equipment occurred. The road segment characteristics of interest were traffic volume, road width, shoulder width, speed limit, road type, and surface type. Traffic volume was assigned based on actual and estimated annual average daily traffic (AADT), which was calculated by the IDOT as the number of motor vehicles driven on a given road 
segment per day. Traffic volume was either physically counted or estimated through a spatial extrapolation method used by the IDOT (AADT was assigned based on surrounding AADT values or AADT values of similar road types and numbers of lanes). Road width was defined as the total width measured in feet, excluding shoulders. Shoulder width, measured in feet, was defined as the sum of the left and right shoulders of a road. Speed limit was defined as the lowest posted speed limit per road segment. This variable was recoded into four categories: $<35,35-45,50-60$, and $60+$. The IDOT classified road type using five road system classifications, and each road segment was grouped into one of the following categories: Interstate, US route, Iowa route, farm to market route, or local route. Farm to market routes are public roads meant specifically for the transport of goods from farms to towns or cities. Local routes are either $25 \mathrm{mph}$ residential roads or $55 \mathrm{mph}$ rural roads. The IDOT classified surface type into 42 categories which were dichotomized into paved (e.g. asphalt, concrete, or brick) or unpaved (e.g. gravel or stone without admixture, grade and drained earth without borrow topping - no shoulder, and unknown).

\section{Analysis}

Cases were defined as road segments that had at least one farm equipment crash. Univariate analyses were used to report the distribution of each variable for all Iowa roads and stratified by crash status. Chi-square or t-test was conducted to examine the relationship between exposure variables and the occurrence of a crash. Collinearity between all covariates was assessed using Pearson correlation. Cochran-Armitage trend test was used to assess a trend in the proportion of farm equipment crashes across categories for traffic volume. Logistic regression models were used to measure the risk of a crash by estimating odds ratios and 95\% confidence intervals. All statistical analyses were conducted using SAS 9.3 for Windows.

\section{Results}

There was a total of 1371 farm equipment crashes reported from 2005 to 2011, and these occurred on 1337 road segments, less than one percent of Iowa's 319,705 road segments. An illustration on the distribution of farm equipment crashes occurring throughout the state of Iowa was created using GIS (Fig. 1). Crashes were randomly dispersed across the state and not confined to an isolated geographic area. The highest percentage of crashes occurred on road segments with an average annual daily traffic count of at least 1251 vehicles (33\%), with posted speed limits between 50 and $60 \mathrm{mph}(79 \%)$ and on paved roads $(70 \%)$ (Table 1 ). The majority of farm equipment crashes occurred on farm to market routes $(43 \%)$, followed by $31 \%$ on local routes.

We found a significant increasing trend in the proportion of farm equipment crashes for traffic volume $(\mathrm{Z}=15.82, p<0.0001$ ) (not tabled). As traffic volume increased, the proportion of farm equipment crashes also increased. Road segments with traffic volume of $361-1250$ or 1251 or more vehicles per day had 7.43 (95\% CI: $5.90-9.34$ ) or 7.00 (95\% CI: 5.38-8.85) times the odds of having a farm equipment crash compared to road segments with traffic volume of 30 or less vehicles

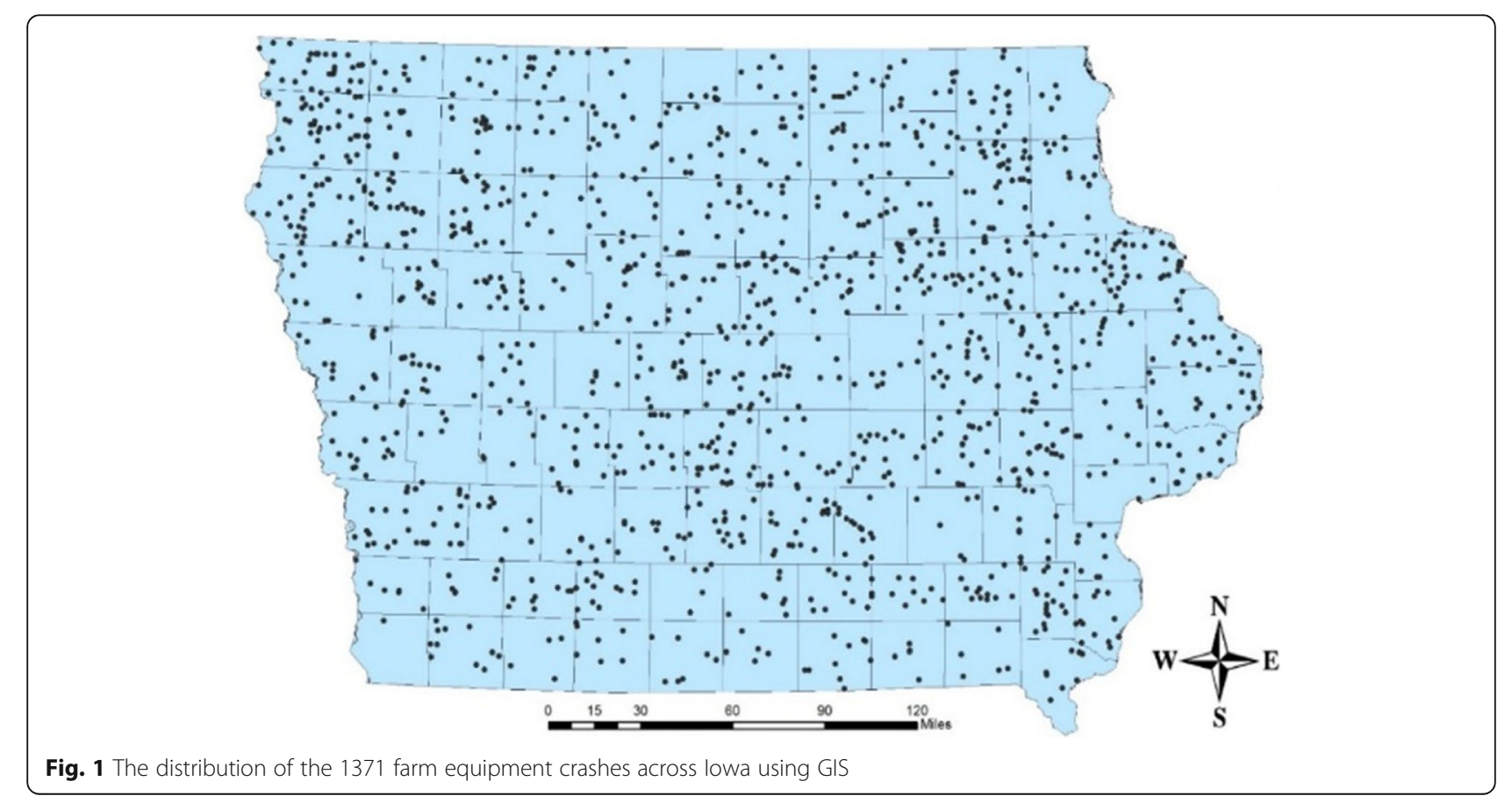


Table 1 Roadway characteristics of all lowa road segments stratified by crash status. N(\%)*

\begin{tabular}{|c|c|c|c|}
\hline & \multicolumn{3}{|l|}{ Road segments } \\
\hline & Without a Crash $(n=318,368)$ & With a Crash $(n=1,337)$ & All lowa Roads $(n=319,705)$ \\
\hline \multicolumn{4}{|c|}{ Road characteristics } \\
\hline \multicolumn{4}{|l|}{ Traffic volume ${ }^{a}$} \\
\hline $0-30$ & $68,068(21.4)$ & $123(9.2)$ & $68,191(21.3)$ \\
\hline $31-101$ & $63,165(19.8)$ & $220(16.5)$ & $63,385(19.8)$ \\
\hline $102-360$ & $62,806(19.7)$ & $192(14.4)$ & $62,998(19.7)$ \\
\hline $361-1250$ & $62,283(19.6)$ & $367(27.5)$ & $62,650(19.6)$ \\
\hline $1251+$ & $62,046(19.5)$ & $435(32.5)$ & $62,481(19.5)$ \\
\hline \multicolumn{4}{|c|}{ Speed limit (mph) } \\
\hline$<35$ & $118,946(37.4)$ & $156(11.7)$ & $119,102(37.3)$ \\
\hline $35-45$ & $18,057(5.7)$ & $85(6.4)$ & $18,142(5.7)$ \\
\hline $50-60$ & $173,207(2.6)$ & $1053(78.8)$ & $174,260(54.5)$ \\
\hline $65+$ & $8,158(2.6)$ & $43(3.2)$ & $8,201(2.6)$ \\
\hline \multicolumn{4}{|l|}{ Road type } \\
\hline Interstate & $5,323(1.7)$ & $6(0.5)$ & $5,329(1.7)$ \\
\hline US Route & $18,265(5.7)$ & $159(11.9)$ & $18,424(5.8)$ \\
\hline lowa Route & $17,425(5.5)$ & $191(14.3)$ & $17,616(5.5)$ \\
\hline FTM Route ${ }^{b}$ & $62,962(19.8)$ & $569(42.6)$ & $63,531(19.9)$ \\
\hline Local Route & $214,393(64.3)$ & $412(30.8)$ & $214,805(67.2)$ \\
\hline \multicolumn{4}{|l|}{ Surface type } \\
\hline Paved & $190,576(59.9)$ & $930(69.6)$ & $191,504(59.9)$ \\
\hline Unpaved & $127,794(40.1)$ & $407(30.4)$ & $128,201(40.1)$ \\
\hline \multicolumn{4}{|l|}{ Road width } \\
\hline mean(sd) & $25.2(7.3)$ & 24.7 (5.8) & $25.2(7.3)$ \\
\hline \multicolumn{4}{|l|}{ Shoulder width } \\
\hline mean(sd) & $4.2(5.6)$ & $7.4(6.2)$ & $4.2(5.6)$ \\
\hline
\end{tabular}

${ }^{a}$ Average Annual Daily Traffic (Total annual traffic volume/365)

${ }^{\mathrm{b}}$ Farm to market route

${ }^{*} P<0.01$ for all variables

per day, respectively (Table 2). Road segments with posted speed limits in the 50-60 mph category had eight times the odds of a crash compared with road segments with less than $35 \mathrm{mph}$ speed limits (95\% CI: 6.59-9.84). US routes $(\mathrm{OR}=4.86,95 \% \mathrm{CI}: 3.99-5.91)$, Iowa routes $(\mathrm{OR}=5.98,95 \% \mathrm{CI}: 4.97-7.20)$, and farm to market routes $(\mathrm{OR}=4.67,95 \% \mathrm{CI}: 4.11-5.32)$ had higher odds of farm equipment crashes compared to local routes, respectively. For every five-foot increase in roadway width, the odds of a crash decreased by $10 \%(\mathrm{OR}=0.90$, CI: 0.86-0.94). For every five-foot increase in shoulder width, the odds of a crash decreased by $6 \%(\mathrm{OR}=0.94$, CI: 0.89-1.00). However, this estimate was marginally statistically significant.

\section{Discussion}

This is the first retrospective cohort study of farm equipment crashes using road segments as the unit of analysis.
As such, this study allows for a robust evaluation of roadway characteristics that increase the risk of a farm equipment crash. We observed a positive dose response relationship between traffic volume and the risk of a crash: as the annual average number of vehicles traveled per day increased, the risk of farm equipment crashes also increased. This suggests that when a piece of farm equipment is on the road with a greater number of vehicles, the increased volume leads to a greater chance of being involved in a crash. Prior research has consistently found that high traffic volume increases crash risk in studies that have not focused specifically on special vehicles like farm equipment (Karlaftis \& Golias 2002; Ackaah \& Salifu 2011; Wang et al. 2009). Wider lane width proved to be a significant protective factor against crashes potentially by decreasing the proximity between farm equipment and opposing traffic (Karlaftis \& Golias 2002). 
Table 2 Odds of farm equipment crashes occurring on lowa road segments calculated using Logistic Regression

\begin{tabular}{|c|c|c|}
\hline & \multicolumn{2}{|c|}{ Farm equipment crash } \\
\hline & $\overline{\operatorname{COR}(95 \% \mathrm{Cl})^{\mathrm{a}}}$ & $\mathrm{aOR}(95 \% \mathrm{Cl})^{\mathrm{b}}$ \\
\hline \multicolumn{3}{|c|}{ Road characteristics } \\
\hline \multicolumn{3}{|l|}{ Traffic volume ${ }^{c}$} \\
\hline $0-30$ & Ref & Ref \\
\hline $31-101$ & $1.93(1.54-2.40)$ & $2.00(1.60-2.49)$ \\
\hline $102-360$ & $1.69(1.35-2.12)$ & $3.76(2.97-4.77)$ \\
\hline $361-1250$ & $3.26(2.66-4.00)$ & $7.43(5.90-9.34)$ \\
\hline $1251+$ & $3.88(3.17-4.74)$ & $7.00(5.38-8.85)$ \\
\hline \multicolumn{3}{|c|}{ Speed limit (mph) } \\
\hline$<35$ & Ref & Ref \\
\hline $35-45$ & $3.59(2.75-4.68)$ & $3.03(2.30-3.99)$ \\
\hline $50-60$ & $4.64(3.92-5.49)$ & $8.05(6.59-9.84)$ \\
\hline $65+$ & $4.02(2.87-5.64)$ & $3.52(2.42-5.14)$ \\
\hline \multicolumn{3}{|l|}{ Road type $e^{e}$} \\
\hline Interstate & $0.59(0.26-1.31)$ & $0.60(0.27-1.35)$ \\
\hline US route & $4.53(3.77-5.44)$ & $4.86(3.99-5.91)$ \\
\hline lowa route & $5.70(4.80-6.78)$ & $5.98(4.97-7.20)$ \\
\hline FTM route ${ }^{f}$ & $4.70(4.14-5.34)$ & $4.67(4.11-5.32)$ \\
\hline Local route & Ref & Ref \\
\hline \multicolumn{3}{|l|}{ Surface type } \\
\hline Paved & Ref & Ref \\
\hline Unpaved & $0.65(0.58-0.73)$ & $0.97(0.86-1.11)$ \\
\hline \multicolumn{3}{|l|}{ Road width ${ }^{9}$} \\
\hline mean(sd) & $0.95(0.91-0.99)$ & $0.90(0.86-0.94)$ \\
\hline \multicolumn{3}{|c|}{ Shoulder width ${ }^{g}$} \\
\hline mean(sd) & 1.44 (1.39-1.49) & $0.94(0.89-1.00)$ \\
\hline
\end{tabular}

${ }^{a}$ Crude odds ratios and $95 \%$ confidence intervals

${ }^{\mathrm{b}}$ Adjusted odds ratios and $95 \%$ confidence intervals; bolded estimates were significant at the $\mathrm{a}=0.05$ level.

'Average Annual Daily Traffic (Total annual traffic volume/365)

${ }^{\mathrm{d}}$ Model mutually controls for Speed Limit, Traffic Volume, and Shoulder Width

Model mutually controls for Road Type, Surface Type and Road Width

fFarm to market route

gUnit: 5 feet

Wider lane and shoulder width were also protective factors in this analysis, associated with at least a $6 \%$ decrease risk in crashing (Hadi et al. 1995; Karlaftis \& Golias 2002). The size of farm equipment ranges between 10 and 25-foot-wide, which is much wider than the standard 12-foot-wide lane (U.S. Interstate Highway System). As a result farm equipment may occupy multiple lanes (Committee on Agricultural Safety and Health Research and Extension 2009). Among citations received by farm equipment operators, $13 \%$ were cited for being left of center, suggesting further that standard roadway lanes are unable to accommodate large farm equipment (Luginbuhl et al. 2003). Furthermore, smaller lanes and lack of shoulders may contribute to farm equipment or other vehicles running off the road, resulting in both collision and non-collision crashes. Lack of road width to maneuver around slow-moving farm equipment can be problematic for drivers of farm equipment and passenger vehicles when navigating the roadways.

During an attempt to pass such a large structure, drivers of non-farm vehicles must enter the opposing lane to determine if it is safe to pass, which may inevitably result in a crash (Kinzenbaw 2008). Furthermore, the frequent presence of towed implemented behind the farm equipment complicates visualization and increases time required to pass (Committee on Agricultural Safety and Health Research and Extension 2009). The validity of these scenarios is supported by the fact that passing collisions are the second most common type of farm equipment collisions (Kinzenbaw 2008; Gkritza et al. 2010) and are usually severe crashes. Of farm equipment crashes that resulted in injury, $22 \%$ of non-farm vehicles were passing the farm equipment (Peek-Asa et al. 2007). With wider shoulders, farm equipment are not only able to pull over in the event of a passing to prevent sideswipes but are also able to drive on the shoulder while staying within the lane.

Road type was also a significant contributor to farm equipment crashes. Farm to market, Iowa and US routes had higher risk of a crash, while interstate roads had the lowest risk. The increased risk observed could be indicative of the increased presence of farm equipment on these types of roads compared with other roads. The inverse may explain the lower risk of farm equipment crashes observed on interstates compared to local routes. In fact, the operation of farm equipment on interstate roads is illegal according Iowa state laws (2014).

Another explanation for the increased risk of crashes particularly on farm to market roads is urban sprawl, which occurs as individuals are widely dispersed into less occupied or dense areas, resulting in long commutes and high traffic exposure (Ewing 1997). As a result, roads that were primarily used for agriculture purposes are now being used more by non-farm vehicles during their commute (Costello et al. 2009). The interaction between suburban or urban motorists and farm equipment operators becomes problematic particularly for drivers unfamiliar with the challenges of sharing the roadway with farm equipment due to its large size, slow speed, and limited maneuverability.

Our study also found that roadways with posted speed limits in the 50-60 mph category were at greater risk for farm equipment crashes. Motorists driving at higher speeds have less time to react to a slow-moving vehicle creating significant challenges for approaching vehicles due to the rate of approach (Kinzenbaw 2008; Jaarsma \& De Vries 2014). To put this into perspective, a passenger vehicle traveling 50-60 mph may potentially close a 400-foot gap with farm equipment moving at a speed of less than 25 mph in less than $10 \mathrm{~s}$ (Schwab 2013). All in $10 \mathrm{~s}$, a driver 
must analyze the situation to identify the potential hazard and determine an adequate reaction, which may not be sufficient time to prevent a crash. The substantial difference in speed provides a plausible explanation for rear-end collisions (20-62\%) being the most frequent type of farm equipment crashes in prior studies (Gerberich et al. 1996; Gkritza et al. 2010) and the high number of "failure to reduce speed" violations received by non-farm vehicle drivers (Hughes \& Rodgman 2000).

Prior research suggests that farmers are highly aware of the safety hazards on high-speed roads. Seventy-seven percent of farmers in North Carolina reported feeling unsafe while driving farm equipment on the roadway due to the speed of other motorists (Luginbuhl et al. 2003). Lack of education on the recognition of the slow-moving vehicle (SMV) emblem, particularly among urban/suburban motorists, was suggested by farmers as the main contributing factor to crashes. To corroborate this statement, a survey conducted by (Garvey 2003) found that less than 30\% of 18-84 year-old drivers were able to correctly state the purpose of the SMV emblem. Two approaches to decrease risk for farm equipment crashes could include driver education to raise awareness of safe practices for sharing the road with farm equipment, or to lower the speed limit of rural roads, specifically on farm to market and local routes. Over the last decade, academic organizations and government agencies have disseminated safe driving information through videos, driver's education manuals, and pamphlets throughout the state on making safer decisions in high traffic areas where farm equipment are present (Kinzenbaw 2008; Iowa's Center for Agricultural Safety and Health 2015). Findings from our study and others can contribute to educational efforts by identifying the environmental or road characteristics that are predictive of farm equipment collisions and providing insights on causes.

\section{Limitations}

Crash data are subject to misclassification of farm equipment involved in a crash, since first responders at the scene are responsible for this categorization. For example, pickup trucks, which may be used as farm equipment, may be classified as passenger vehicles or farm equipment, although they do not share the same risk factors as farm implements. We excluded pick-up trucks from the farm equipment category if make and model were available on reports. This exclusion and misclassification may have underestimated the effects observed in this study. Another limitation is the lack of roadway travel data specific to farm equipment, which limits the interpretation of our findings. For example, while traffic volume is available for each road segment, we do not know how many farm equipment travelled on a particular road segment, if at all. Unfortunately, traffic counts are not reported by vehicle type.

\section{Conclusion}

Despite these limitations, our findings contribute to the traffic and agricultural literature in a number of substantive ways. We found that increased traffic volume, posted speed limits, and smaller roadway widths were all significantly associated with the occurrence of farm equipment crashes. Findings from this study can be used to effectively guide the development of policies that promote the education of roadway users on sharing the roadway with farm equipment and of engineering initiatives to design safer public roadways for all road users.

\section{Appendix}

Table 3 Roadway Characteristics that Demarcate IDOT Road Segments

Change in divided roadway to non-divided roadway, or vice versa

Significant change in outside shoulder width (0.6 meters or more)

Significant change in median width (0.6 meters or more)

Change in surface type

Change in surface width

Change from two-way to one-way street, or vice versa

Section with "Y" in SPECIAL STUDY

Change in surface condition rating (two points or more)

Change in state functional classification

\section{Additional file}

Additional file 1: List of roadway characteristics that demarcate lowa road segments. (XLSX $97076 \mathrm{~kb})$

\begin{abstract}
Acknowledgements
We would like to acknowledge the lowa Department of Transportation for providing us with the data and answering all our inquiries. We would also like to acknowledge the farm crash working group for providing their feedback on the study design and analytical approach.
\end{abstract}

\section{Funding}

This work was supported by the University of lowa Great Plains Center for Agricultural Safety and Health, Centers for Disease Control and Prevention, National Institute of Occupational Safety and Health [U50 OH007548-11]. The findings and conclusions in this journal article are those of the author(s) and do not necessarily represent the official position of the Centers for Disease Control and Prevention.

Availability of data and materials

The dataset supporting the conclusions of this article is included within the article and its additional file 1.

\section{Authors' contribution}

MG contributed to the study design, acquisition of the data, analysis, and drafting of the manuscript. MT contributed to the analysis, interpretation of the results and the drafting/revision of the manuscript. CP contributed to the study design, interpretation of the results, and revision of the manuscript. DR contributed to the study design, interpretation of the results, and revision of the manuscript. MR contributed to the study conception and design, acquisition of the data, interpretation of the results, and drafting/revision of the manuscript. All authors read and approved the final manuscript. 


\section{Competing interests}

The authors declare that they have no competing interests.

Received: 5 July 2016 Accepted: 22 November 2016

Published online: 20 December 2016

\section{References}

Ackaah W, Salifu M. Crash prediction model for two-lane rural highways in the Ashanti region of Ghana. IATSS Res. 2011;35(1):34-40.

Bureau of Labor Statistics U.S. Departement of Labor. Census of Fatal Occupational Injuries Charts 2013. 2015. Available from: http://www.bls.gov/ iif/oshwc/cfoi/cftb0287.pdf.

Committee on Agricultural Safety and Health Research and Extension. 2009. Agricultural Equipment on Public Roads. USDA-CSREES, Washington, DC.

Costello TM, Schulman MD, Mitchell RE. Risk factors for a farm vehicle public road crash. Accid Anal Prev. 2009;41(1):42-7.

Ewing R. Is Los Angeles-style sprawl desirable? J Am Plan Assoc. 1997;63(1):107-26.

Garvey PM. Motorist comprehension of the slow-moving vehicle (SMV) emblem. J Agric Saf Health. 2003;9(2):159-69.

Gerberich SG, Robertson LS, Gibson RW, Renier C. An epidemiological study of roadway fatalities related to farm vehicles: United States, 1988 to 1993. J Occup Environ Med. 1996:38(11):1135-40.

Gkritza K, Kinzenbaw CR, Hallmark S, Hawkins N. An empirical analysis of farm vehicle crash injury severities on lowa's public road system. Accid Anal Prev. 2010;42(4):1392-7.

Hadi MA, Aruldhas J, Chow L-F, Wattleworth JA. Estimating safety effects of crosssection design for various highway types using negative binomial regression. Transp Res Rec. 1995;1500:169.

Harland KK, Greenan M, Ramirez M. Not just a rural occurrence: Differences in agricultural equipment crash characteristics by rural-urban crash site and proximity to town. Accid Anal Prev. 2014;70:8-13.

Hughes R, Rodgman E. Crashes involving farm tractors and other farm vehicles/ equipment in North Carolina 1995-1999. 2000.

lowa Department of Transportation. Spring is here-share the road with farm equipment. 2015. Available from: http://www.transportationmatters.iowadot. gov/2015/04/spring-is-here-share-the-road-with-farm-equipment.html.

lowa Code 423.1. Streamlined sales and use tax act. 2014. Available from: https:// coolice.legis.iowa.gov/Cool-ICE/default.asp?category=billinfo\&service= lowaCode\&ga $=83 \&$ input $=423$.

lowa's Center for Agricultural Safety and Health. Staying Safe on lowa's Rural Roads. lowa City: University of lowa, College of Public Health Uol; 2015.

Jaarsma CF, De Vries JR. Agricultural Vehicles and Rural Road Safety: Tackling a Persistent Problem. Traffic Inj Prev. 2014;15(1):94-101.

Karlaftis MG, Golias I. Effects of road geometry and traffic volumes on rural roadway accident rates. Accid Anal Prev. 2002;34(3):357-65.

Kinzenbaw CR. Improving safety for slow-moving vehicles on lowa's high speed rural roadways: ProQuest. 2008.

Luginbuhl R, Jones VC, Langley RL. Farmers' perceptions and concerns: the risks of driving farm vehicles on rural roadways in North Carolina. J Agric Saf Health. 2003:9(4):327-48.

Peek-Asa C, Sprince N, Whitten P, Falb S, Madsen M, Zwerling C. Characteristics of crashes with farm equipment that increase potential for injury. J Rural Health. 2007;23(4):339-47.

Schwab C. In: Outreach ISUEa, editor. Use SMV emblems for your safety. Iowa: lowa States University Extension and Outreach; 2013.

Wang C, Quddus MA, Ison SG. Impact of traffic congestion on road accidents: a spatial analysis of the M25 motorway in England. Accid Anal Prev. 2009:41(4): 798-808.

\section{Submit your manuscript to a SpringerOpen ${ }^{\circ}$ journal and benefit from:}

- Convenient online submission

- Rigorous peer review

- Immediate publication on acceptance

- Open access: articles freely available online

- High visibility within the field

- Retaining the copyright to your article 